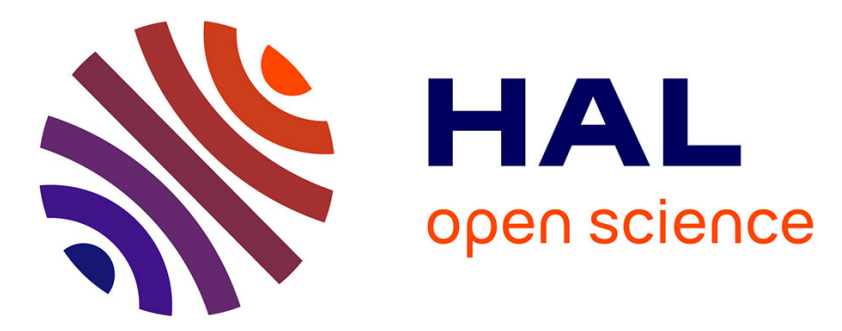

\title{
Structure of a new ternary compound with high magnesium content, so-called Gd13Ni9Mg78
}

Samuel Couillaud, Etienne Gaudin, François Weill, Sonia Gomez, Cristina

Stan, Damien Planté, Salvatore Miraglia, Jean-Louis Bobet

\section{- To cite this version:}

Samuel Couillaud, Etienne Gaudin, François Weill, Sonia Gomez, Cristina Stan, et al.. Structure of a new ternary compound with high magnesium content, so-called Gd13Ni9Mg78. Acta Materialia, 2012, 60 (10), pp.4144-4151. 10.1016/j.actamat.2012.04.012 . hal-00702386

\section{HAL Id: hal-00702386 \\ https://hal.science/hal-00702386}

Submitted on 7 Jun 2012

HAL is a multi-disciplinary open access archive for the deposit and dissemination of scientific research documents, whether they are published or not. The documents may come from teaching and research institutions in France or abroad, or from public or private research centers.
L'archive ouverte pluridisciplinaire HAL, est destinée au dépôt et à la diffusion de documents scientifiques de niveau recherche, publiés ou non, émanant des établissements d'enseignement et de recherche français ou étrangers, des laboratoires publics ou privés. 


\title{
Structure of a new ternary compound with high magnesium content,
} so-called $\mathrm{Gd}_{13} \mathrm{Ni}_{9} \mathrm{Mg}_{78}$.

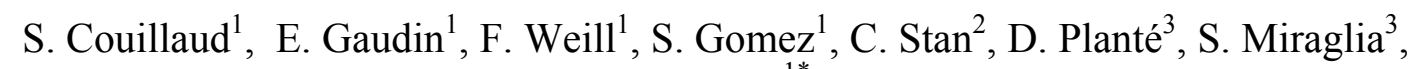 \\ JL. Bobet ${ }^{*}$ \\ (1) CNRS, Université de Bordeaux, ICMCB, 87 avenue du Docteur Albert Schweitzer, \\ 33608 Pessac Cedex, France \\ (2) Institute of Physical Chemistry 'Ilie Murgulescu', 202 Splaiul Independentei Street, \\ P.O. Box 194, 060021 Bucharest, Romania \\ (3) Institut NEEL and CRETA, CNRS, BP 166, 38042 Grenoble cedex, France
}

E-mail: bobet@icmcb-bordeaux.cnrs.fr

* Author to whom any correspondence should be addressed 


\section{Abstract}

The magnesium metal rich composition $\mathrm{Gd}_{13} \mathrm{Ni}_{9} \mathrm{Mg}_{78}$ was synthesized from the elements in sealed tantalum tubes in an induction furnace. According to the X-ray diffraction, the EPMA analyses and the dark field images obtained by TEM, a new compound with a composition ranging from $\mathrm{Gd}_{10-15} \mathrm{Ni}_{8-12} \mathrm{Mg}_{72-78}$ and low crystallinity was brought to light.

In order to increase the crystallinity, different experimental conditions were investigated for numerous compounds with the initial composition $\mathrm{Gd}_{13} \mathrm{Ni}_{9} \mathrm{Mg}_{78}$. Also, several heat treatments (from $573 \mathrm{~K}$ to $823 \mathrm{~K}$ ) and cooling rates (from room temperature quenched down to $2 \mathrm{~K} / \mathrm{h}$ ) have been tested. The best crystallinity was obtained for the slower cooling rates ranging from 2 to $6 \mathrm{~K} / \mathrm{h}$.

From the more crystallized compounds, the structure was partially deduced using the transmission electron microscopy and an average cubic structure with lattice parameter $\mathrm{a}=4.55 \AA$ could be assumed. A modulation along both $\mathrm{a}^{*}$ and $\mathrm{b}^{*}$ axis with vectors of modulation $q 1=0.42 \mathrm{a} *$ and $q 2=0.42 \mathrm{~b} *$ was observed.

This compound so-called $\mathrm{Gd}_{13} \mathrm{Ni}_{9} \mathrm{Mg}_{78}$ absorbs around $3 \mathrm{wt} \%$ of hydrogen at $603 \mathrm{~K}$, 30 bars and some fair reversibility is possible, because after the first hydrogenation, irreversible decomposition into $\mathrm{MgH}_{2}, \mathrm{GdH}_{2}$ and $\mathrm{NiMgH}_{4}$ has been shown. The pathway of the reaction is described herein. The powder mixture after decomposition shows an interesting kinetics for magnesium without ball milling.

Keywords: Rare-earth intermetallics, Magnesium, Nanocrystallite, Hydrogen storage 


\section{Introduction}

The RE-TM-Mg systems (with RE = rare earth and TM = Transition Metal) have been intensively investigated in recent years. Several systems were already identified such as:

(i) the compounds with the higher $\mathrm{RE}$ content: $\mathrm{RE}_{4} \mathrm{NiMg}$ (with $\mathrm{RE}=\mathrm{Y}, \mathrm{Pr}-\mathrm{Nd}, \mathrm{Sm}$, Gd-Tm, Lu) [1] crystallizing in the large cubic structure, $a=13-14 \AA$, space group F-43m.

(ii) the compounds with the higher $\mathrm{TM}$ content : $\mathrm{RENi}_{4} \mathrm{Mg}$ (with $\mathrm{RE}=\mathrm{La}, \mathrm{Ce}, \mathrm{Nd}, \mathrm{Gd}$ and $\mathrm{Y}$ ) [2-3] which crystallize in the $\mathrm{F}-43 \mathrm{~m}$ space group (cubic $\mathrm{MgCu}_{4} \mathrm{Sn}$ structure type, known as $\mathrm{C} 15 \mathrm{~b}$ ), with a lattice parameter from 7.03 to $7.18 \AA$,

(iii) the equiatomic compounds: $\mathrm{RENiMg}$ (with $\mathrm{RE}=\mathrm{La}$ and $\mathrm{Ce}$ ) [4] crystallizing in orthorhombic structure (Ima2 space group) with the lattice parameters $\mathrm{a} \approx 8.54 \AA, \mathrm{b} \approx 13.10 \AA$ and $\mathrm{c} \approx 7.36 \AA$,

(iv) and other compounds with, for example, the composition $\mathrm{RETMMg}_{2}, \mathrm{RE}_{2} \mathrm{TM}_{3} \mathrm{Mg}_{3}$, $\mathrm{RE}_{2} \mathrm{TM}_{2} \mathrm{Mg}, \mathrm{RETM}_{9} \mathrm{Mg}_{2}, \mathrm{RETM}_{2} \mathrm{Mg}, \ldots$ [4].

More recently, the $\mathrm{Mg}$ rich part of ternary diagrams has also been studied. Solokha et al. have identified 2 new ternary phases with high magnesium content :

- $\mathrm{RECuMg}_{4}$ (with $\mathrm{RE}=\mathrm{La}, \mathrm{Tb}, \mathrm{Y}$ ) [5-6] crystallizing in tetragonal structure $(\mathrm{a}=10.39 \AA, \mathrm{c}=4.51 \AA)$ for $\mathrm{La}$ compound and orthorhombic structure $(\mathrm{a}=13.5 \AA$, $\mathrm{b}=20.3 \AA, \mathrm{c}=3.9 \AA$ ) for $\mathrm{Tb}$ and $\mathrm{Y}$

- $\mathrm{Tb}_{2} \mathrm{Ni}_{2} \mathrm{Mg}_{3}$ [7] which crystallizes with an orthorhombic structure, with the lattice parameters $\mathrm{a}=3.978 \AA, \mathrm{b}=21.203 \AA, \mathrm{c}=3.6583 \AA$.

However the Mg rich part of the ternary diagrams RE-TM-Mg is still not well known. As it is now established that these compounds can have interesting mechanical properties $[8,9]$ and good hydrogenation properties [10], the study of the system Gd-Ni-Mg (rich Mg part) was the aim of this work.

First, a new compound was identified with a low crystallinity for the initial composition $\mathrm{Gd}_{13} \mathrm{Ni}_{9} \mathrm{Mg}_{78}$. Other tests with composition close to this nominal composition (e.g. $\mathrm{Gd}_{11.8} \mathrm{Ni}_{5.8} \mathrm{Mg}_{82.4}$ and $\mathrm{Gd}_{13.4} \mathrm{Ni}_{12.2} \mathrm{Mg}_{74.4}$ ) lead to the same results in terms of structure meaning that the compounds can exist in a certain range of composition. These new phases are referred to in the text as $\mathrm{Gd}_{13} \mathrm{Ni}_{9} \mathrm{Mg}_{78}$. In this paper we report (i) the crystallographic properties of $\mathrm{Gd}_{13} \mathrm{Ni}_{9} \mathrm{Mg}_{78}$ and (ii) the relationship between experimental conditions and crystallinity and (iii) the hydrogen sorption properties.

\section{Experimental details}


Starting materials for the preparation of the sample were gadolinium pieces (Stream Chemicals, > $99.9 \%$ ), nickel rod (Stream Chemicals, > $99.9 \%$ ), and magnesium rod (alpha Aesar, $>99.8 \%$ ). To avoid oxides impurities, the surfaces of the magnesium and gadolinium pieces were cleaned in the glove box. Elemental pieces were then weighed in the appropriate amounts and sealed in tantalum ampoules under an argon pressure of ca. 800 mbar. The argon used was purified before with magnesium sponge $(673 \mathrm{~K})$. Then, the ampoules were heated at about $1373 \mathrm{~K}$ (high frequency furnace or resistance furnace) and kept at this temperature for 2-10 min. The ampoules were then placed in a quartz tube and sealed under vacuum to be annealed at different temperature (from $573 \mathrm{~K}$ to $823 \mathrm{~K}$ ) for two weeks. No reaction with the tantalum tubes was observed. The polycrystalline samples were found to be stable in air.

All polycrystalline samples were characterized with X-ray powder diffraction using a Philips PW 1050 diffractometer with $\mathrm{CuK} \alpha$ radiation $(\lambda=0.15405 \mathrm{~nm})$. These patterns were scanned by steps of $0.02^{\circ}(2 \theta)$ from $5^{\circ}$ to $80^{\circ}$ with a constant counting time of $30 \mathrm{~s}$.

The bulk samples were investigated by electron probe microanalyses (EPMA) with metallic $\mathrm{Gd}\left(\mathrm{L}_{\alpha}\right)$, $\mathrm{Ni}\left(\mathrm{K}_{\alpha}\right)$ and $\mathrm{Mg}\left(\mathrm{K}_{\alpha}\right)$ as standards. The bulk samples were embedded in a methylmetacrylate matrix and the surface was polished with different silica and diamond pastes. The surface remained unetched for the EPMA measurements. The quantitative analyses were in good agreement with the initial compositions.

TEM images and electron diffraction experiments were performed using respectively JEOL $22200 \mathrm{FS}$ and JEOL $2000 \mathrm{FX}$ microscope equipped with double tilt specimen holder. It was used at an accelerating voltage of $200 \mathrm{kV}$. The powder was ground in ethanol and a droplet of this suspension was then deposited on a carbon - formvar copper grid.

Hydrogen kinetics sorption were investigated by use of an automatic Sievert-type volumetric apparatus (HERA, Hydrogen Storage System) in the temperature range from room temperature to $603 \mathrm{~K}$ and with 10 bar and 0.2 bar of $\mathrm{H}_{2}$ for absorption and desorption respectively [11]. 


\section{Results and Discussion}

\subsection{Effects of experimental conditions on the crystallinity of $G d_{13} \mathrm{Ni}_{9} \mathrm{Mg}_{78}$ compound}

The X-Ray powder pattern of $13 \mathrm{Gd}+9 \mathrm{Ni}+78 \mathrm{Mg}$ melted (called $\mathrm{Gd}_{13} \mathrm{Ni}_{9} \mathrm{Mg}_{78}$ in this paper) is shown in figure 1. Few diffraction peaks and a broad amorphous peak (in the range $22^{\circ} \leq 2 \theta \leq 40^{\circ}$ ) are observed. The low signal/background ratio indicates that the crystallinity of the as-cast sample is poor. Nevertheless, the major peaks can be indexed with a facecentered cubic structure (FCC) with $\mathrm{a} \approx 4.55 \AA$, but some peaks (marked with a star on figure 1) remain not indexed. However, this hypothesis agrees well with a hypothetic theoretical FCC structure. Indeed, if the stoichiometry and the metal radii of each element in the compound are considered, an average metallic radius of $1.59 \AA$ is obtained (e.g. $0.13 \times \mathrm{r}_{\mathrm{Gd}}+0.09 \times \mathrm{r}_{\mathrm{Ni}}+0.78 \times \mathrm{r}_{\mathrm{Mg}}$ ). This value leads to a lattice parameter $\mathrm{a}=4.5 \AA$ if $\mathrm{a}$ perfect contact between atoms in FCC stacking is considered.

Therefore, the crystallinity is too weak to go further on the structure of the compound. For that purpose, the experimental conditions have been optimized to increase the crystallinity. Two parameters were selected:

- $\quad$ the heat treatment temperature from $573 \mathrm{~K}$ to $823 \mathrm{~K}$ for 2 weeks

- the rate of cooling from air quenched down to $2 \mathrm{~K} / \mathrm{h}$.

All the tested experimental conditions are reported in table 1. The samples are numbered from 1 to 13 with the initial name GNM (e.g. for Gd-Ni-Mg ternary compounds).

The X-Ray patterns of each sample are given in figure 2. The major diffraction peaks observed in figure 1 are visible for each X-ray pattern. However, some differences allow to separate the X-Ray patterns into two groups:

- Group I: The samples which are cooled quickly (almost air-quenched) and heat-treated at temperature higher than $673 \mathrm{~K}$ (i.e. GNM1-8). For these samples, the major part of diffraction peaks can be indexed with the FCC structure with a lattice parameter $\mathrm{a} \approx$ $4.55 \AA$. Moreover, as observed for the first sample (fig. 1), the low signal/background ratio indicates a bad crystanility for these samples.

- Group II: The samples which are cooled slowly down to $673 \mathrm{~K}, 573 \mathrm{~K}$ or $323 \mathrm{~K}$ (i.e. GNM9-13). As for compounds of group I, the major part of diffraction peaks can be indexed with FCC structure (i.e. $\mathrm{a} \approx 4.55 \AA$ ). However, the signal/background ratio is higher 
and at least two new peaks appear. The one at $2 \theta=48.5^{\circ}$ can be indexed with the (112) plan of the cubic structure which induces a loss of $\mathrm{F}$ mode. To explain the peak, around $8^{\circ}$, the hypothesis of a superstructure (confirmed latter by TEM analysis) with lattice parameter $\mathrm{a} \approx$ $22.8 \AA$ (i.e. $\mathrm{a} * 5)$, can be done.

To simplify the discussion, only the sample GNM1, GNM2 of group I and GNM12, GNM13 of group II are going to be considered in the following. The X-ray patterns of these 4 samples are isolated and presented in figure 3. From the higher peak of each X-ray pattern (i.e. around $34^{\circ}$ ), the crystallite size was estimated using Scherrer's formula and given in table 2. Even if the absolute value must be considered with caution, the values can be compared between each over. The crystallite sizes are going from $32 \mathrm{~nm}$ to $49 \mathrm{~nm}$ and increase (i) slightly when the heat treatment temperature decreases and (ii) more significantly when the rate of cooling decreases. It should be concluded that the rate of cooling is probably the predominant factor to increase the crystallinity.

All compounds have been characterized by EPMA (figure 4). Two different microstructures are observed : (i) GNM1 and GNM2 can be described as a mixture of two phases with 2 compositions slightly different and of both sides of the initial composition (e.g. $\mathrm{Gd}_{16} \mathrm{Ni}_{12} \mathrm{Mg}_{72}$ and $\mathrm{Gd}_{11} \mathrm{Ni}_{8} \mathrm{Mg}_{81}$ for GNM2), (ii) for GNM12 and GNM13 only one phase exists with the composition $\mathrm{Gd}_{11 \pm 0.5} \mathrm{Ni}_{8 \pm 0.5} \mathrm{Mg}_{81 \pm 0.5}$. For GNM12, it could be possible to highlight two different contrasts but each of then correspond to the same composition for more than fifty points measured. For GNM13 the picture given in figure 4 presents the worst areas where some gadolinium oxides were observed which explain the slightly lower gadolinium content of the ternary phase. From this figure 4, it is clear that the cooling conditions strongly affect the microstructure. Moreover, the EPMA analyses demonstrate the existence of different compositions going from 10 to $15 \%$ at. for $\mathrm{Gd}$, from 8 to $12 \%$ at. for $\mathrm{Ni}$ and from 72 to $78 \%$ at. for $\mathrm{Mg}$ (i.e. $\mathrm{Gd}_{10-15} \mathrm{Ni}_{8-12} \mathrm{Mg}_{72-78}$ ) while the $\mathrm{X}$-Ray patterns are similar. It means that the new compound with the initial composition $\mathrm{Gd}_{13} \mathrm{Ni}_{9} \mathrm{Mg}_{78}$ exist in a large domain. Nevertheless, we will continue to name it $\mathrm{Gd}_{13} \mathrm{Ni}_{9} \mathrm{Mg}_{78}$ in the following.

The TEM dark field pictures given in figure 5 highlights another difference between samples of group I (i.e. GNM1 and 2, figure 5.a-b) and sample of group II (i.e. GNM13, figure 5-c). For samples of group I, the crystallites (which appear bright on the picture) are distributed randomly in the sample with a size ranging from 1 to 10 nanometer. For GNM13 compound (and also for GNM12 not show here) larger crystallites of about $200 \mathrm{~nm}$ are 
observed. This observation agrees well with the information deduced from X-Ray pattern (table 2).

Selected area electron diffraction patterns for GNM1 and GNM2, confirm the low crystallinity as it has not been possible to select one single crystallite (because of the limit dimension of the diaphragm). So, for both samples the electron diffraction patterns obtained are characteristic of a polycrystalline sample, which explain the existence of some spot of diffraction. The presence of more defined spots of diffraction for GNM2 is due to the domains of crystallinity which are bigger. Moreover, both show amorphous halos which confirm the low crystallinity of the samples. However this information could be distorted by the sample holder in carbon. The higher crystallinity of the group II samples allow to make electron diffraction patterns usable to get structural information.

\subsection{Information on crystal structure of $\mathrm{Gd}_{13} \mathrm{Ni}_{9} \mathrm{Mg} g_{78}$ compound}

According to the previous results, efforts were focussed on the groupe II samples. The TEM was then a unique tool according to the relative low crystallinity of the sample. Both samples (i.e. GNM12 and 13) have the same metric and the same symmetry. In figure 6, some electron diffraction patterns are presented. The picture 6.b was obtained on GNM12 sample while the others (figure 6.a,c-d) were obtained from GNM13 sample.

In figure 6.a and 6.b, it is possible to observe both the 4 fold and 3 fold symmetry axis. Both are coherent with the hypothetic cubic structure. Moreover, the most intense spots can be indexed considering a lattice parameter $\mathrm{a} \approx 4.55 \AA$. The electron diffraction patterns presented on figures 6.c and 6.d, are respectively obtained by rotating the crystallite along $\mathrm{a}^{*}$ and $\mathrm{b}^{*}$ axis with the same angle in accordance with a cubic symmetry. This observation is an additional proof of the cubic symmetry.

The projection of the cubic symmetry with lattice parameter $\mathrm{a} \approx 4.55 \AA$ is drawn on the figure 6.a and the unindexed spots of diffraction can be taken into account by considering a superstructure with $\mathrm{a}^{\prime}=5 \mathrm{a}$ as previously considered to explain the peak at about $8^{\circ}$ on XRD powder patterns. To confirm this hypothesis, the evolution of spots intensity observed along one direction (from figure 6.d) was studied (figure 7). In figure 7, it appears that the spots of the superstructure are not equidistant (as shown by the red arrows on figure 7). To index all spots along this direction, it is necessary to introduce a modulation vector $q 1=0.42 \mathrm{a}^{*}$. The spots observed between the more intense spots are the satellites of order 1 or 2 (sometimes 3 ) 
and the indexation is proposed on figure 7. As the modulation vector is slightly higher than 0.4 (the one for a 5a superstructure) the distance between the more intense spot and the two subsequent is smaller. For the $3^{\text {rd }}$ order, it is even possible to see a shoulder (i.e. leading to an asymmetry of the peak). The same information was obtained along axis $b^{*}$. Unfortunately and because of the small size of the crystallites, it has not been possible to get information along the $c^{*}$ axis. However the spots observed between two planes on the electron diffraction patterns (shown by red arrows on the figure 6.c-d) could be induced by the same modulation along $\mathrm{c}^{*}$.

On all electron diffraction patterns (figure 6) a diffusion phenomenon is observed and confirms the low crystallinity of the sample. So, the $\mathrm{Gd}_{13} \mathrm{Ni}_{9} \mathrm{Mg}_{81}$ compound has a long range order characterized by the modulation and a crystallographic disorder characterized by the diffusion. The disorder is confirmed by the high resolution picture (figure 8), where ordered and disordered areas are observed. Moreover, the periodic repartition of the intensity found on the ordered areas confirms the cubic structure of lattice parameter $\mathrm{a} \approx 4.55 \AA$. Complex crystal structures were also observed for other rich magnesium compounds (e.g. $\mathrm{LaMg}_{\sim 11}$, $\left.\mathrm{Mg}_{35} \mathrm{Zn}_{3} \mathrm{RE}_{4}, \mathrm{Mg}_{29} \mathrm{Zn}_{3} \mathrm{RE}_{4}\right)$, which present long-range order [12,13]

\subsection{Preliminary hydrogenation behaviour}

$\mathrm{Gd}_{13} \mathrm{Ni}_{9} \mathrm{Mg}_{78}$ (sample GNM12) has been subjected to hydrogen pressure at different temperatures in the range from room temperature to $603 \mathrm{~K}$. At first, at $603 \mathrm{~K}$ and under 30 bars, the full absorption is obtained after $5 \mathrm{~h}$. Such low kinetic is assumed to be due to the existence of oxides layers. X-Ray diffraction performed after absorption (figure 9) shows that $\mathrm{Gd}_{13} \mathrm{Ni}_{9} \mathrm{Mg}_{78}$ compound is decomposed into $\mathrm{GdH}_{2}, \mathrm{MgH}_{2}$ and $\mathrm{Mg}_{2} \mathrm{NiH}_{4}$. A same effect has already been reported for the ternary compound $\mathrm{LaCuMg}_{8}$ which decomposes irreversibly into $\mathrm{LaH}_{3}, \mathrm{MgCu}_{2}$ and $\mathrm{MgH}_{2}$ after 20h [14].

After the desorption at $573 \mathrm{~K}$ under $1.10^{-4}$ bar of $\mathrm{H}_{2}$, the X-Ray pattern presented in figure 9 highlights the presence of 3 phases: $\mathrm{GdH}_{2}, \mathrm{Mg}_{2} \mathrm{Ni}$ and $\mathrm{Mg}$ proving that the ternary compound no longer exist. The decomposition is then irreversible and only $\mathrm{Mg}_{2} \mathrm{Ni}$ and $\mathrm{Mg}$ phases will react further with hydrogen. The reaction path of hydruration could then be written as follows:

(i) First step reaction (irreversible)

$$
\mathrm{Gd}_{13} \mathrm{Ni}_{9} \mathrm{Mg}_{78}+91 \mathrm{H}_{2} \rightarrow 13 \mathrm{GdH}_{2}+9 \mathrm{Mg}_{2} \mathrm{NiH}_{4}+60 \mathrm{MgH}_{2}
$$


(ii) Second step reaction (reversible)

$$
13 \mathrm{GdH}_{2}+9 \mathrm{Mg}_{2} \mathrm{NiH}_{4}+60 \mathrm{MgH}_{2} \Leftrightarrow 13 \mathrm{GdH}_{2}+9 \mathrm{Mg}_{2} \mathrm{Ni}+60 \mathrm{Mg}+78 \mathrm{H}_{2}
$$

In order to test the reversibility of the second step reaction, absorption/desorption cycles were done at $573 \mathrm{~K}$ on the powder decomposed, called " $\mathrm{Gd}_{13} \mathrm{Ni}_{9} \mathrm{Mg}_{78}$ activated powder" (figure 10). The sample absorbs about 3\%wt of hydrogen with good kinetics (i.e. full absorption after $10 \mathrm{~min}$ ). This capacity agrees well with the theoretical capacity of $3.4 \% \mathrm{wt}$ deduced from the reaction 2. For desorption, all hydrogen (i.e. $3 \% \mathrm{wt}$ ) is released in less than 3 min. So, the second step reaction is fully reversible and a good sorption kinetic is obtained. The subsequent kinetics of the absorption and desorption at different temperatures are given in figure 11 and figure 12 respectively. As expected, it is shown that decreasing the temperature leads to a decrease of the kinetic but also of the maximum capacity. Nevertheless, the absorption is possible at room temperature and a full desorption is also observed at temperature as low as $533 \mathrm{~K}$. These kinetics are comparable with the ones obtained by Zaluska et al.[15] and Li et al. [16] on ball milled $\mathrm{MgH}_{2}+\mathrm{Mg}_{2} \mathrm{NiH}_{4}$. Indeed for a mixture milled in the proportion $65-35 \% \mathrm{wt}$, Zaluska et al. get a good kinetic and a desorption temperature reduced from $100 \mathrm{~K}$ versus pure $\mathrm{MgH}_{2}$. They explain this improvement by the presence of $\mathrm{Mg}_{2} \mathrm{NiH}_{4}$. A same observation was done on the mixture $\mathrm{Mg}+\mathrm{Ni}-\mathrm{Y}(20 \% \mathrm{wt})$ milled $40 \mathrm{~h}$. In this case the improvement of the kinetics is explained by the dual catalytic effect of $\mathrm{YH}_{3}$ and $\mathrm{Mg}_{2} \mathrm{NiH}_{4}$

So, it could be concluded that " $\mathrm{Gd}_{13} \mathrm{Ni}_{9} \mathrm{Mg}_{78}$ activated powder" exhibit a good kinetics without any ball milling. Moreover, the results confirm the interest of the decomposition under hydrogen of the ternary compounds to obtain highly reactive powder [17].

\section{Conclusion}

The new compound so-called $\mathrm{Gd}_{13} \mathrm{Ni}_{9} \mathrm{Mg}_{78}$ was discovered in the Gd-Ni-Mg system. In fact, this compound exists in a large domain going from 10 to 15 for $\mathrm{Gd}$, from 8 to 12 for $\mathrm{Ni}$ and from 72 to 78 for $\mathrm{Mg}$ (i.e. $\mathrm{Gd}_{10-15} \mathrm{Ni}_{8-12} \mathrm{Mg}_{72-78}$ ). The low crystallinity of the compound has been improved with different heat treatments and rate of cooling. The best crystallinity was obtained for the samples which were cooled slowly (i.e. 2-6 K/h). According to the TEM measurements and in agreement with the preliminary XRD powder studies, $\mathrm{Gd}_{13} \mathrm{Ni}_{9} \mathrm{Mg}_{78}$ 
crystallizes in an average cubic structure $\mathrm{a} \approx 4.5 \AA$ with a modulation along both axis $\mathrm{a}^{*}$ and $\mathrm{b}^{*}$ with vectors $q 1=0.42 \mathrm{a} *$ and $q 2=0.42 \mathrm{~b} *$.

$\mathrm{Gd}_{13} \mathrm{Ni}_{9} \mathrm{Mg}_{77}$ absorbs hydrogen at $603 \mathrm{~K}$ and 10 bars, but the absorption leads to an irreversible decomposition into $\mathrm{MgH}_{2}, \mathrm{GdH}_{2}$ and $\mathrm{Mg}_{2} \mathrm{NiH}_{2}$. Reversibility of the reaction was observed for both couples: $\mathrm{Mg} / \mathrm{MgH}_{2}$ and $\mathrm{Mg}_{2} \mathrm{Ni} / \mathrm{Mg}_{2} \mathrm{NiH}_{4}$ with kinetics and temperatures comparable with the ones obtained on ball milled $\mathrm{MgH}_{2}+\mathrm{Mg}_{2} \mathrm{NiH}_{4}$. Indeed, the absorption is possible at room temperature and a full desorption is also observed at temperature as low as $533 \mathrm{~K}$. It makes such compound very promising for several hydrogen applications. 
[1] Tuncel S, Roquefere JG, Stan C, Bobet JL, Chevalier B, Gaudin E, Hoffmann RD, Rodewald Ute-Ch, Pöttgen R. J Solid State Chem 2009; 182:229

[2] Guénée L, Favre-Nicolin V, Yvon K. J AlloysCompd 2003; 348:129

[3] Bobet JL, Lesportes P, Roquefere JG, Chevalier B, Asano K, Sakaki K, Akiba E. Int J Hydrogen Energy 2007; 32:2422

[4] Rodewald Ute-Ch, Chevalier B, Pöttgen R. J Solid State Chem 2007; 180:1720

[5] Solokha P, De Negri S, Pavlyuk V, Saccone A, Marciniak B. J Solid State Chem 2007; 180:3066

[6] De Negri S, Solokha P, Saccone A, Pavlyuk V. Intermetallics 2009; 17:614

[7] Solokha P, De Negri S, Saccone A, Pavlyuk V, Marciniak B, Tedenac JC. Acta Crystallogr 2007; C63:i13

[8] Caceres CH, Davidson CJ, Griffiths JR, Newton CL. Mater Sci Eng 2002; A325:344

[9] Hagihara K, Kinoshita A, Sugino Y, Yamasaki M, Kawamura Y, Yasuda HY, Umakoshi Y. Acta Mater 2010; 58:6282

[10] Schlapbach L, Züttel A. Nature 2001; 414:353

[11] Schulz R, Boily S, Huot J. Patent 09/424,331 1999

[12] Denys RV, Poletaev AA, Solberg JK, Tarasov BP, Yartys VA. Acta Mater 2010; $58: 2510$

[13] Egusa D, Abe E. Acta Mater 2012; 60:166

[14] Couillaud S, Gaudin E, Bobet JL. Intermetallics 2011 ; 19:336 
[15] Zaluska A, Zaluski L, Ström-Olsen JO. J AlloysCompd 1999; 289:197

[16] Li Z, Liu L, Jiang L, Wang S. Int J Hydrogen Energy 2007; 32:1869

[17] Couillaud S, Gaudin E, Andrieux J, Gorsse S, Gayot M, Bobet JL, submitted to Int J Hydrogen Energy 


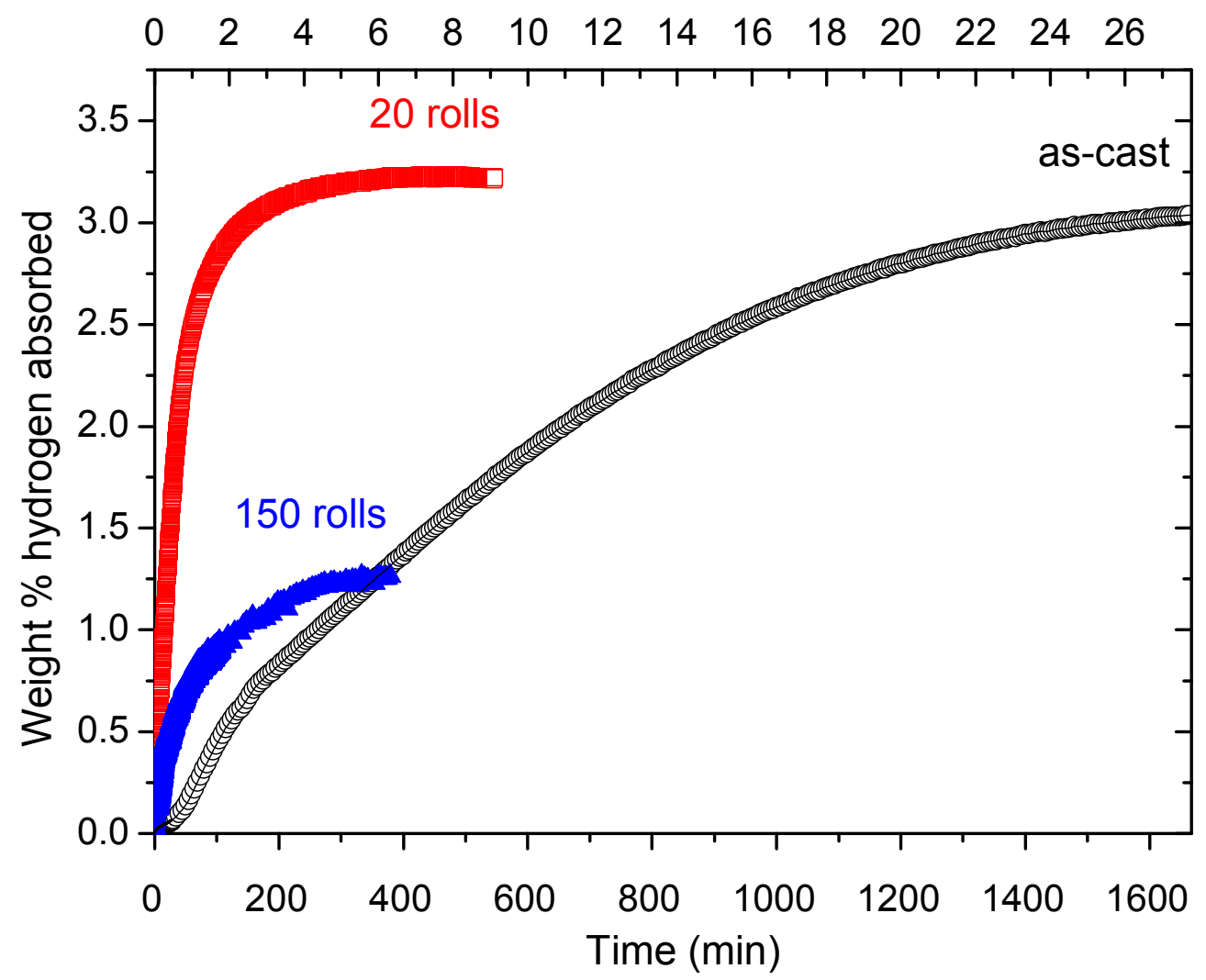

Figure 1 : Hydrogen absorption kinetics under 10 bar of $\mathrm{H}_{2}$ and $300{ }^{\circ} \mathrm{C}$, for $\mathrm{LaCuMg}_{8}$ as-cast (black circle) and for $\mathrm{LaCuMg}_{8}$ cold-rolled 20 (red square) and 150 times (blue triangle).

Time (h)

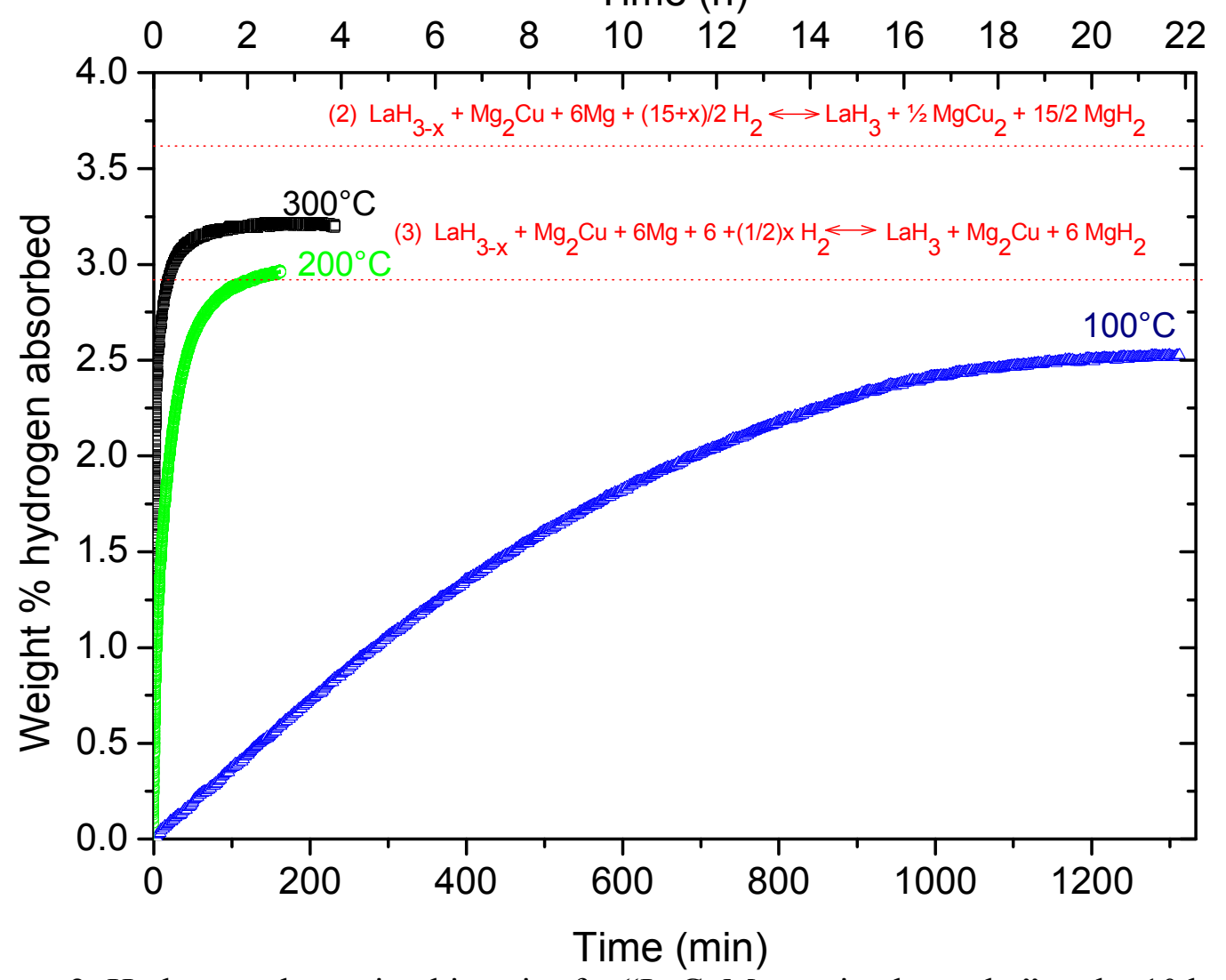

Figure 2: Hydrogen absorption kinectics for " $\mathrm{LaCuMg}_{8}$ actived powder" under 10 bar of $\mathrm{H}_{2}$ and $100{ }^{\circ} \mathrm{C}$ (blue triangle), $200{ }^{\circ} \mathrm{C}$ (green circle) and $300{ }^{\circ} \mathrm{C}$ (black square). The dashed lines show theoretical hydrogen uptakes according to reaction (2) and (3), of $3.6 \mathrm{wt} \%$ and $2.9 \mathrm{wt} \%$ respectively. 


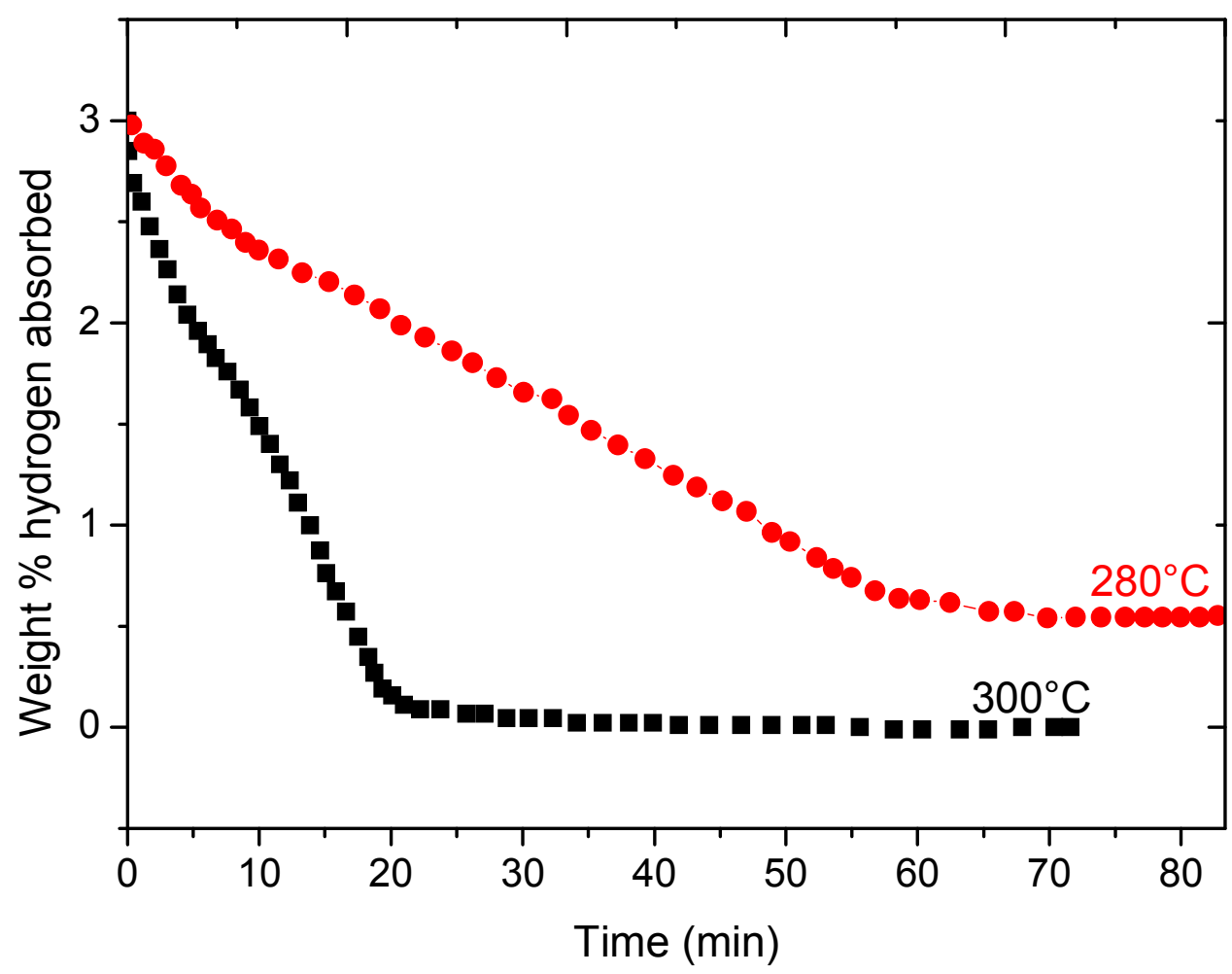

Figure 3: Hydrogen desorption for " $\mathrm{LaCuMg}_{8}$ actived powder" under 0.2 bar of $\mathrm{H}_{2}$ and $280{ }^{\circ} \mathrm{C}$ (red circle) and $300^{\circ} \mathrm{C}$ (black square).

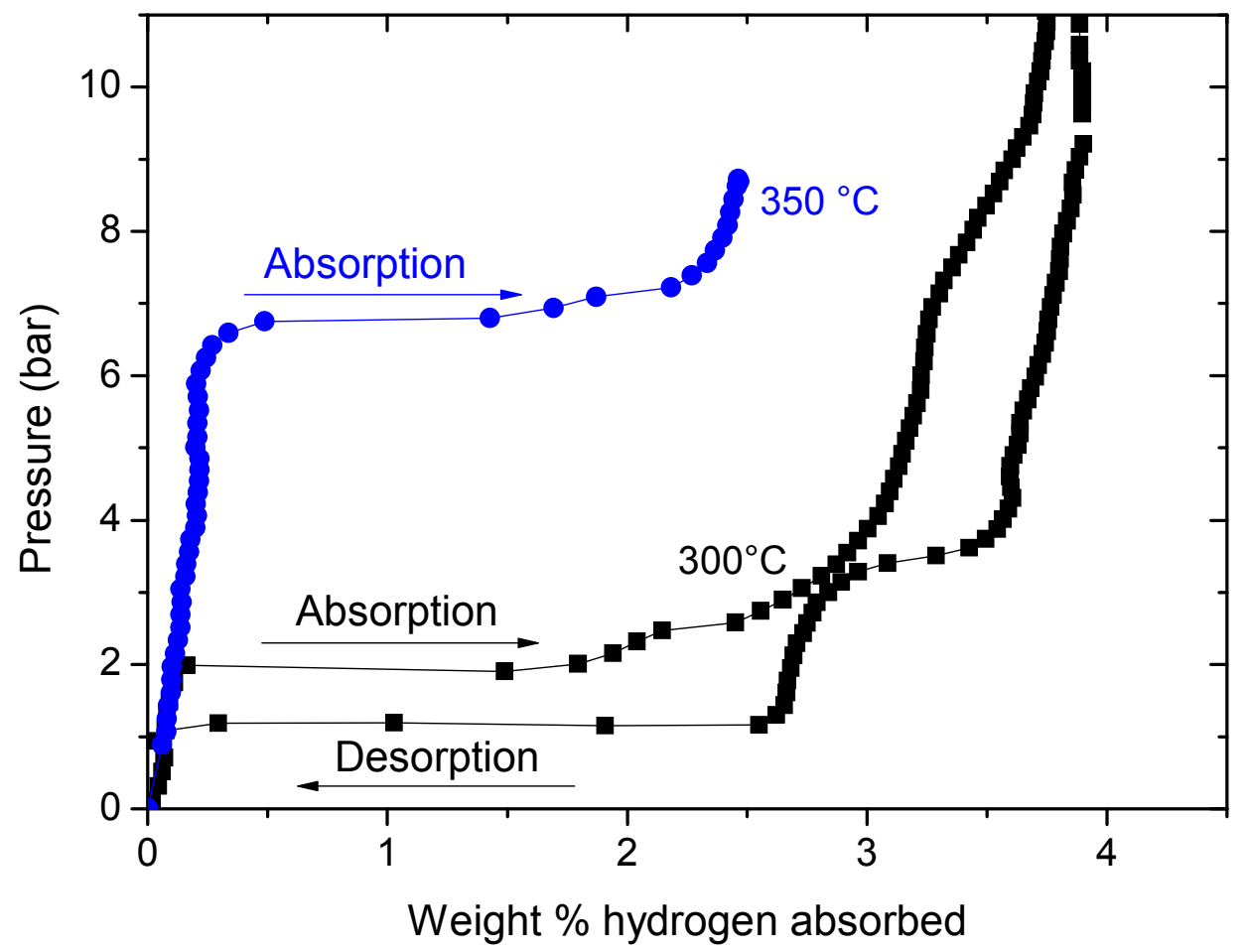

Figure 4 : PCT curves of " $\mathrm{LaCuMg}_{8}$ activated powder" under hydrogen at $300{ }^{\circ} \mathrm{C}$ (black square) and $350^{\circ} \mathrm{C}$ (blue circle). 


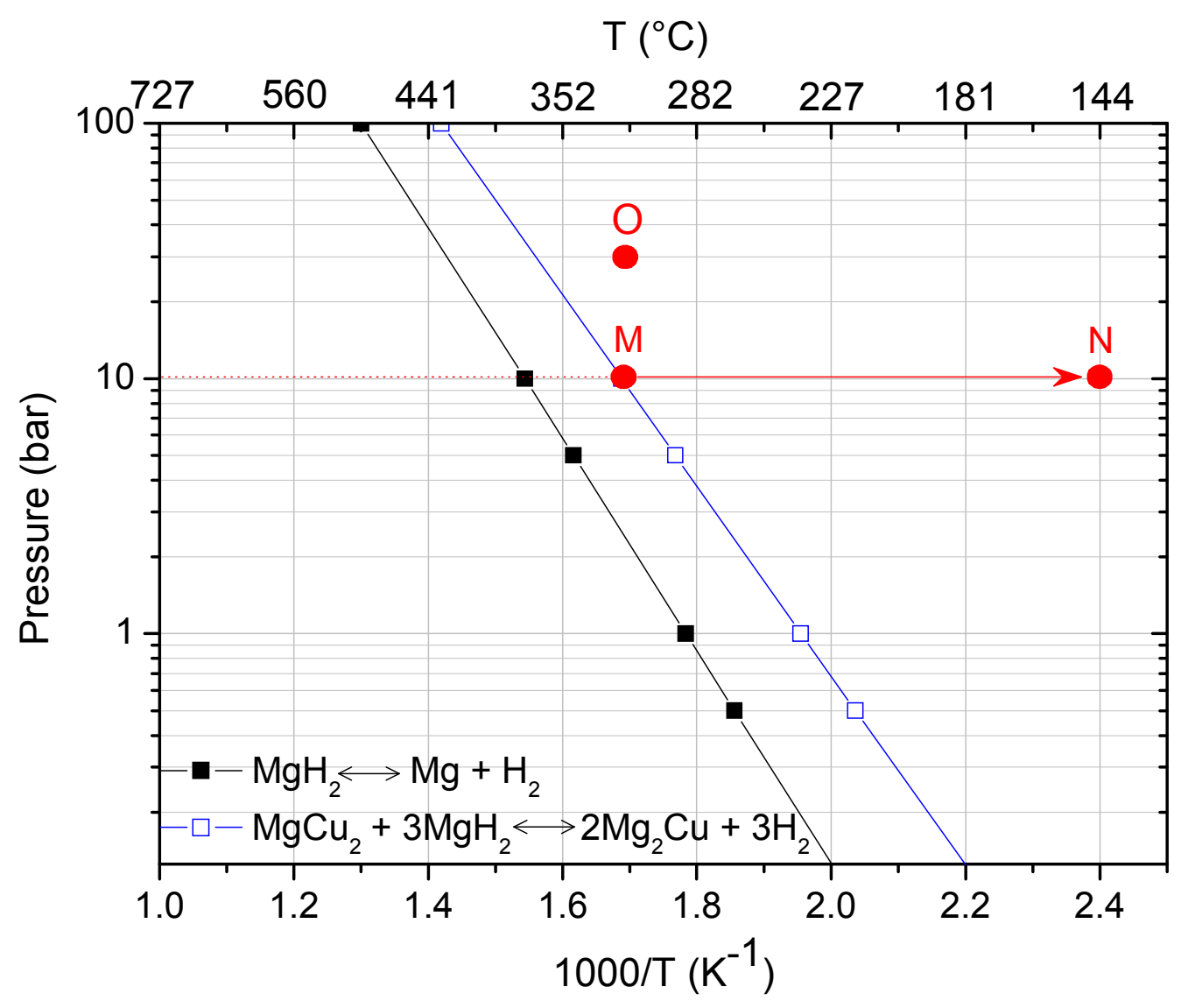

Figure 5 : Calculated Van't Hoff plots of the various reactions for the destabilization of magnesium hydride. 

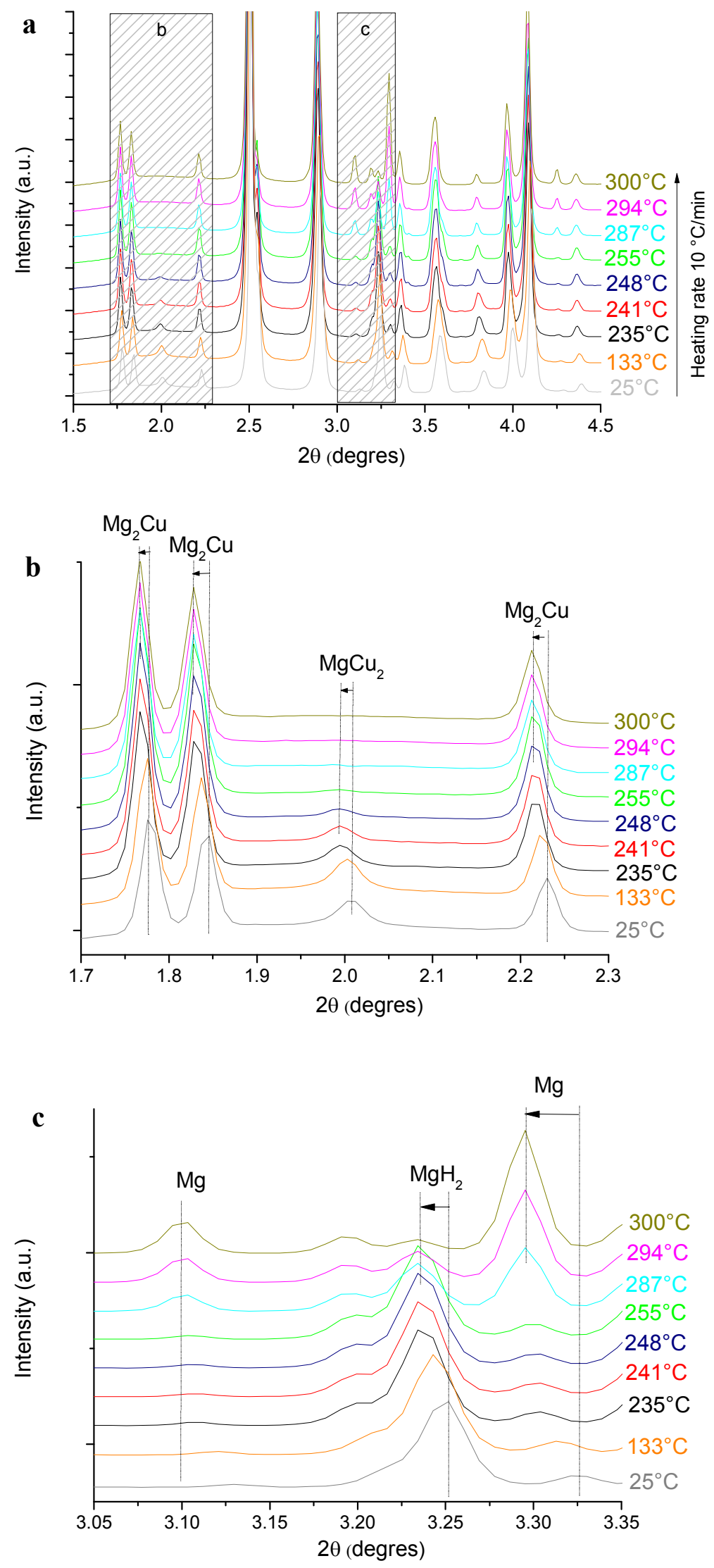

Figure 6 : In-situ synchrotron X-Ray diffraction of " $\mathrm{LaCuMg}_{8}$ activated powder" during the desorption step (from $25{ }^{\circ} \mathrm{C}$ to $300{ }^{\circ} \mathrm{C}$ at $10{ }^{\circ} \mathrm{C} / \mathrm{min}$ ) under argon flow $\left(500 \mathrm{~mL} \cdot \mathrm{m}^{-1}\right)$. The figure $\mathrm{b}$ and $\mathrm{c}$ are the enlarged portions of figure a indicated by hatched zones. 

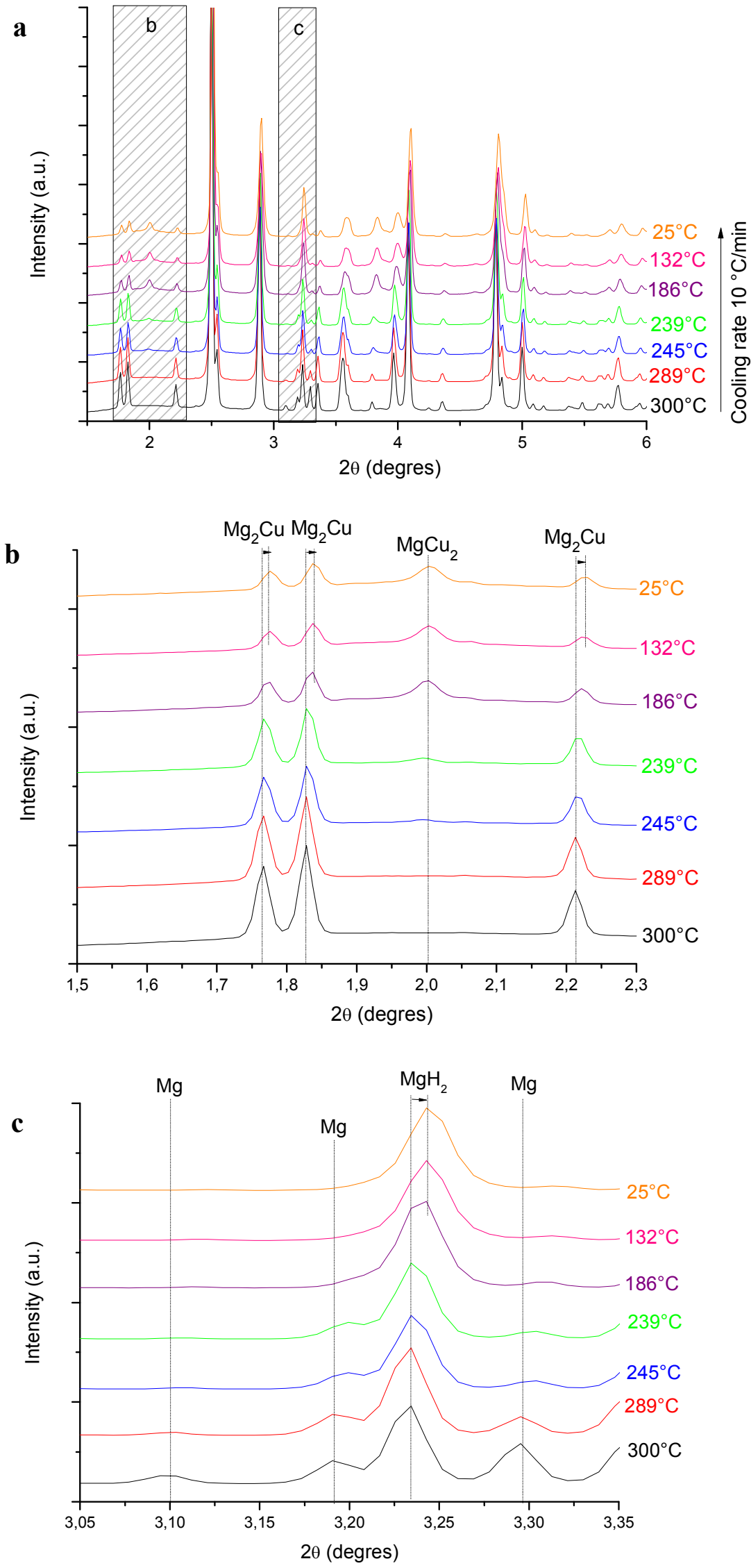

Figure 7 : In-situ synchrotron X-Ray diffraction of " $\mathrm{LaCuMg}_{8}$ activated powder" during the absorption step (from $300{ }^{\circ} \mathrm{C}$ to $25^{\circ} \mathrm{C}$ at $10{ }^{\circ} \mathrm{C} / \mathrm{min}$ ) under 30 bar of hydrogen. The figure $\mathrm{b}$ and $\mathrm{c}$ are the enlarged portions of figure a indicated by hatched zones. 

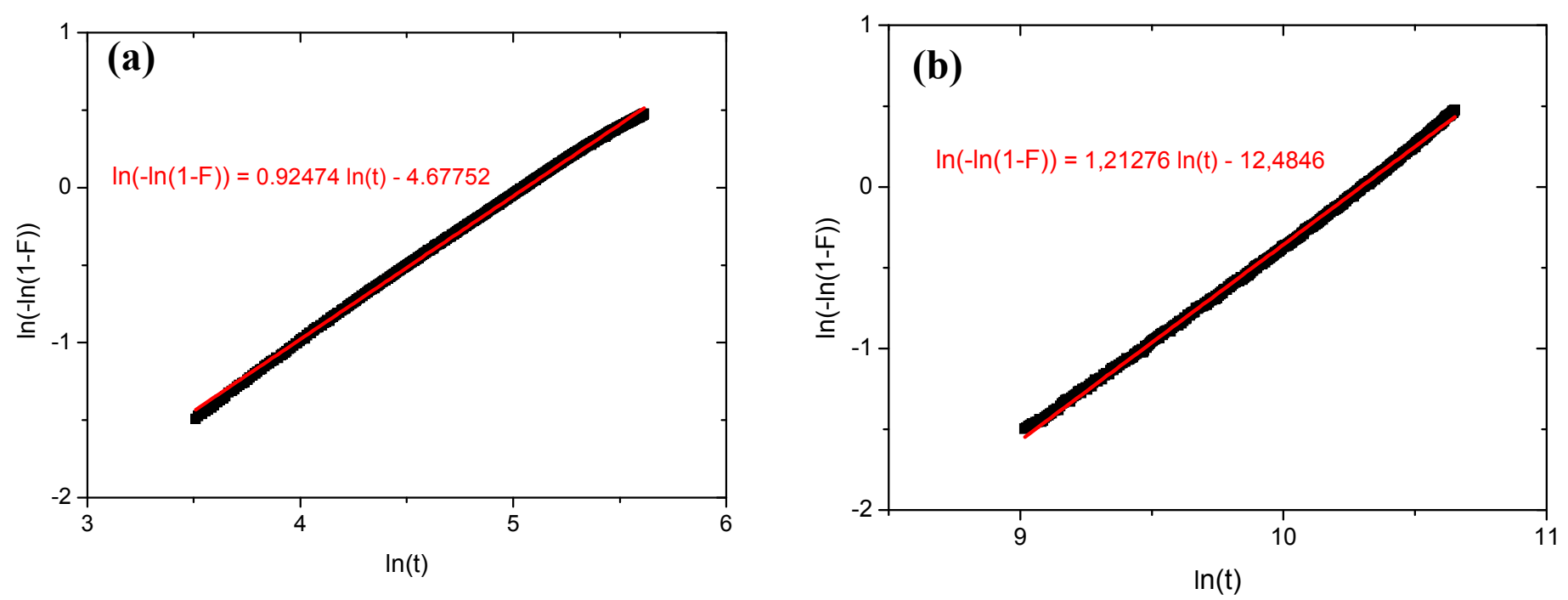

Figure $8: \ln (-\ln (1-\mathrm{F}))$ versus $\ln (\mathrm{t})$ plot for the absorption kinetics at $300{ }^{\circ} \mathrm{C}$ (a) and $100{ }^{\circ} \mathrm{C}(\mathrm{b})$ of " $\mathrm{LaCuMg}_{8}$ activated powder".

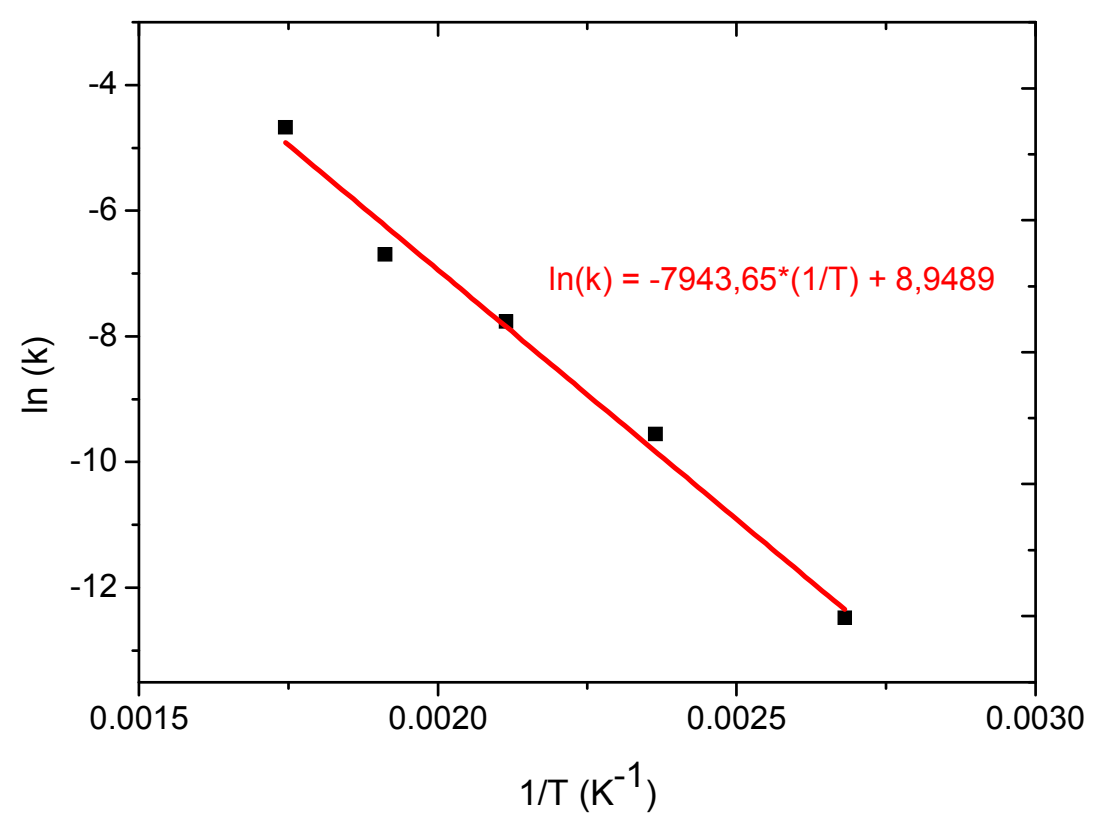

Figure 9 : Arrhenius plot for the determination of the activation energy of " $\mathrm{LaCuMg}_{8}$ activated powder". 


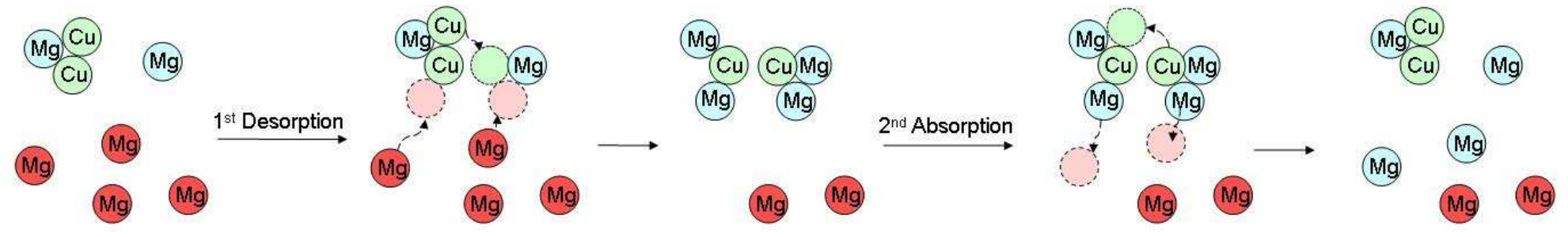

Figure 10 : Scheme describing the mechanism of the transformation $\mathrm{Mg}_{2} \mathrm{Cu} / \mathrm{MgCu}_{2}$ during sorption cycles.

Table 1: Comparison between the mixture $\mathrm{MgH}_{2}+\mathrm{MgCu}_{2}$ of Andreasen work's [32] and our " $\mathrm{LaCuMg}_{8}$ activated powder" for absorption and desorption.

\begin{tabular}{|l|c|c|c|c|}
\hline & $\begin{array}{c}\text { \%wt hydrogen absorbed/ } \\
\text { theoretical \%wt hydrogen }(\mathbf{\%})\end{array}$ & $\begin{array}{c}\text { Temperature } \\
\left({ }^{\circ} \mathbf{C}\right)\end{array}$ & Time (h) & Ref \\
\hline Absorption & 93 & 325 & 12 & {$[32]$} \\
\hline Desorption & 89 & 300 & 1 & $\begin{array}{c}\text { Our } \\
\text { work }\end{array}$ \\
\hline & 88 & 360 & 6 & {$[32]$} \\
& 92 & 300 & 0.41 & $\begin{array}{c}\text { Our } \\
\text { work }\end{array}$ \\
\hline
\end{tabular}



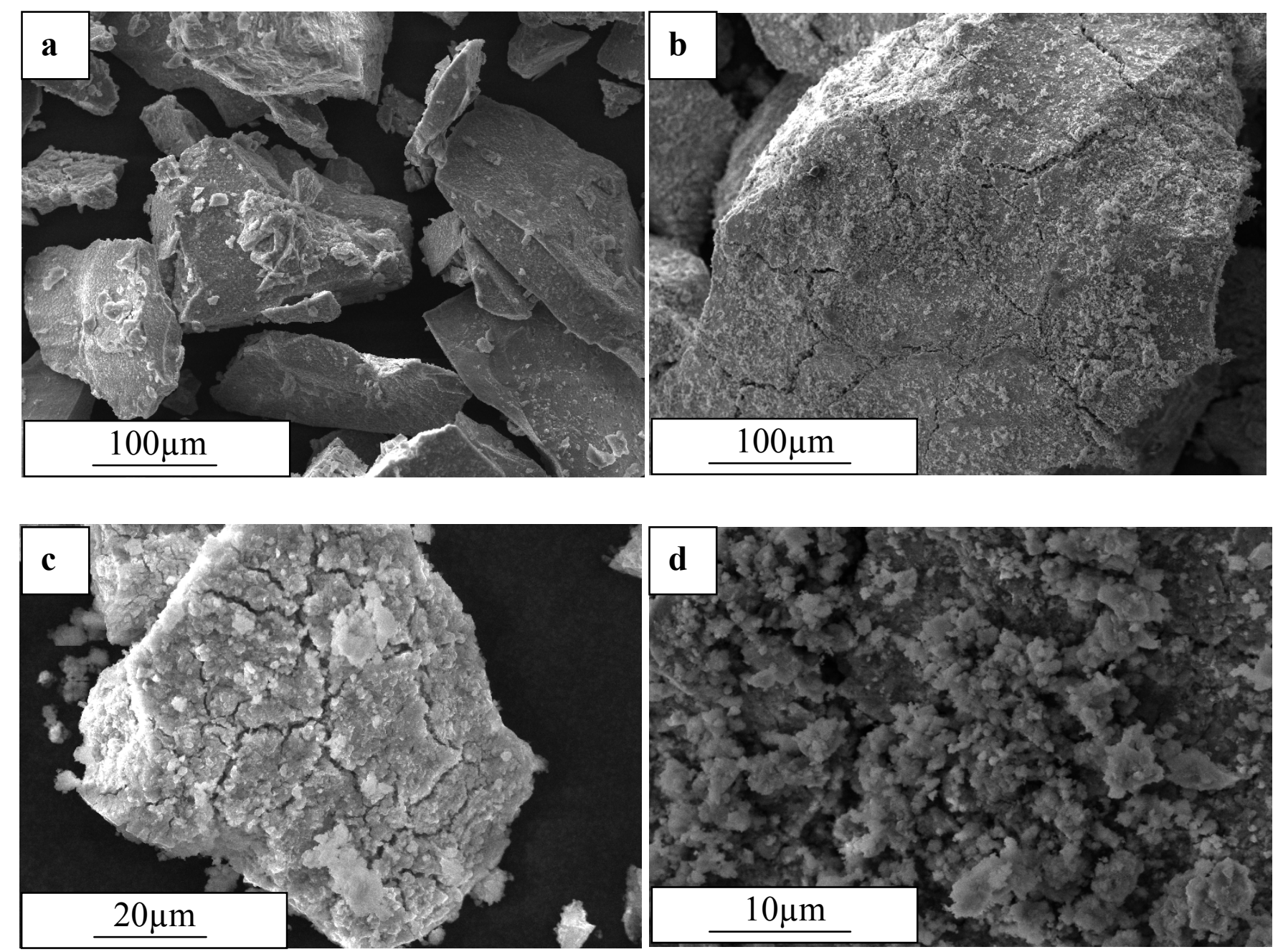

Figure 11 : SEM pictures (secondary electron) of " $\mathrm{LaCuMg}_{8}$ activated powder" after decomposition (a) and after 4 absorption/desorption cycles (b, c, d). 


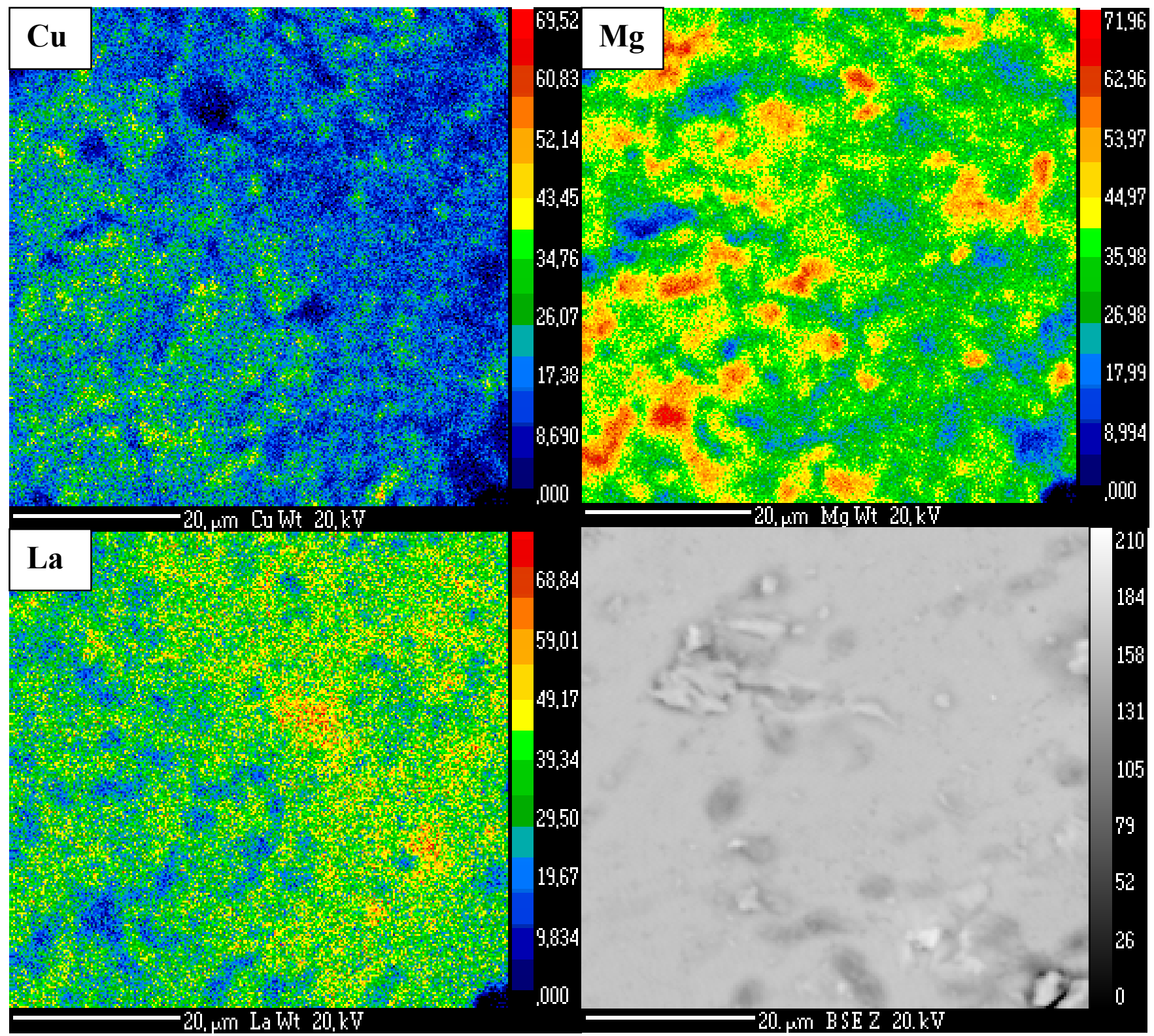

Figure 12: EPMA analysis of one grain of " $\mathrm{LaCuMg}_{8}$ activated compound" after four absorption/desorption cycles. The three first pictures represent the repartition of one element (i.e. $\mathrm{Cu}, \mathrm{Mg}, \mathrm{La}$ ) inside the grain. The last one is the BSE picture. 